\title{
Epidemiological study of ocular trauma in SNMC and HSK hospital Bagalkot
}

\author{
Arathi Choudhary ${ }^{1}$, Monalisha Pattnaik,"* \\ ${ }^{\mathbf{1}}$ Assistant Professor, ${ }^{2}$ Post Graduate Student, Dept. of Ophthalmology, S. Nijlingappa Medical College and HSK Hospital, \\ Karnataka, India
}

*Corresponding Author:

Email: dr.lisa009@gmail.com

\begin{abstract}
Aim: To study the epidemiology of ocular trauma in a medical college hospital in North Karnataka region.

Materials and Methods: Demographic data, detail history and ocular examination were done for all the patients who presented to our hospital between the periods of August 2016 to April 2017 with any ocular trauma. Data were collected and analyzed using Open- Epi software.

Result: 104 patients presented to our hospital during the time period of 9months. The mean age of trauma was 32.78 with SD 16.97. Male ( $65.38 \%$ ) were more affected than female(34.61\%).57.69\% were from rural and $42.3 \%$ were from urban. Ocular trauma mostly occurs between 30-50 years (41.3\%). Home, road and field were the most common location of ocular injury. Foreign body, stick and lime were the most common offending agent. The association between age of ocular trauma and location of injury and occupation was clinically significant with $\mathrm{p}$ value 0.05 and 0.041 respectively. The association between gender and location of injury was clinically significant with p value 0.0013 but occupation and gender of ocular trauma was clinically not significant with $\mathrm{p}$ value 0.08 .

Conclusion: Considering the prevalence, middle aged men are more vulnerable to ocular trauma mostly while working at field or driving. Prognosis might be challenging. Appropriate education for eye protection and use of safety measures, would help in reducing ocular morbidity. Educating for timely treatment and intervention after injury is helpful for saving vision.
\end{abstract}

Keyword: Epidemiology, Ocular trauma, Rural.

\section{Introduction}

Ocular trauma is one of the major causes of blindness and disabilities in developing countries, though it is preventable in majority of cases. The current study aimed to identify the prevalence and epidemiology of ocular trauma, which has a vital role in planning for reduction of their prevalence. Ocular trauma causes a serious health burden. A number of studies on eye injuries have been reported in literature. But these studies focus on specific types of trauma, have a small sample or were conducted in industrialized countries but our study was done in general population attending tertiary eye care unit. ${ }^{1-4}$

\section{Materials and Methods}

This was a prospective study of sample size of 104 patients, who attended our hospital during the period of August 2016 to April 2017 with any ocular trauma. The Ethical committee of our Institute approved this study and it met the criteria of Helsinki Declaration on human experimentation. The written informed consent was taken from individual patients in their own language.

Personal information and detailed history was taken including age, gender, type of injury, ocular structures involved, time interval between the injury and presentation. All patients under went ocular examination which included visual acuity, anterior segment examination by slit lamp (Haag Streit), fundus examination was done using 90 diopter lens and IOP measurement was done.
Visual acuity of each eye was tested with Snellen's visual acuity chart. The projection and perception of light was tested with a well-focused torch light.

Minor injury of lid and adenexal tissue was repaired under local anaesthesia for adult patients and for children under sedation or general anaesthesia. Patients were followed up after 24 hours, 1 week and 6 weeks.

We classified intraocular injuries according to Birmingham Eye Trauma Terminology (BETT)

A person with open globe was admitted and operated under local anaesthesia at the earliest. The cornea and sclera were sutured using 10/0 nylon sutures. We did not remove any damaged part of the lid or anterior segment of the eye. In the case of traumatic cataract, we removed cataract, implanted an intraocular lens. During their postoperative visits, vision was noted as presented as well as with the best correction.

The data was collected on a pre-tested form. The information was entered on a spread sheet using Microsoft Excel. We conducted a univariate analysis of the parametric method and used Statistical Package for Social Studies version 18 (SPSS).

\section{Result}

Out of 1074 patients who presented to Ophthalmology OPD, SNMC \& HSK Hospital, Bagalkot, 104 patients had ocular/orbital trauma during the time period of 9 months. Males $(65.38 \%)$ were more affected than females $(34.61 \%) .57 .69 \%$ were from rural and $42.3 \%$ were from urban. 


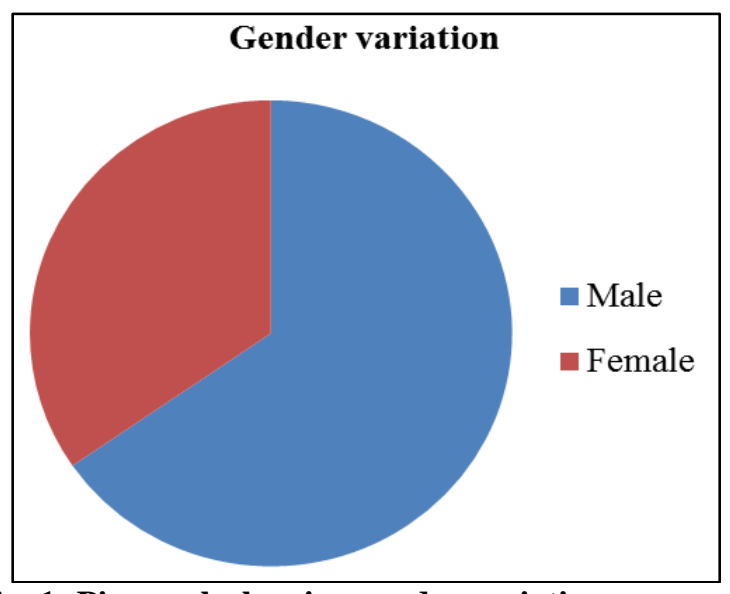

Fig. 1: Pie graph showing gender variation

Among all the patients $57.69 \%$ patients belonged to rural area and $42.3 \%$ belonged to urban area.

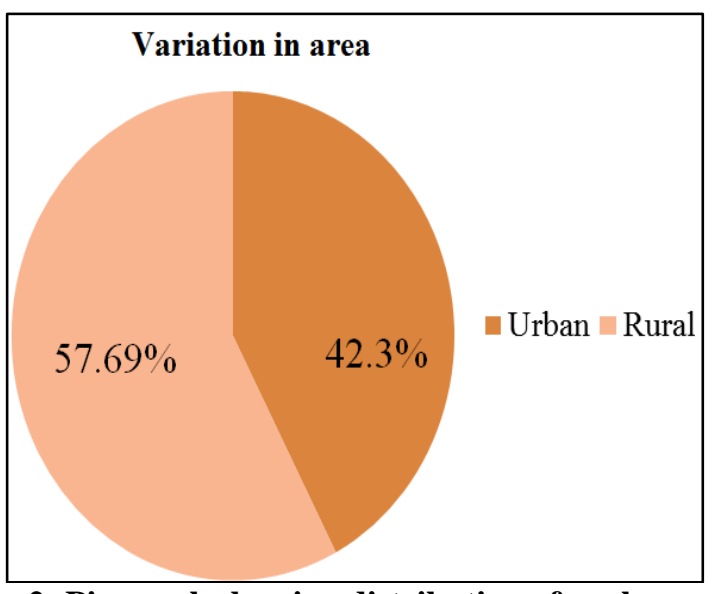

Fig. 2: Pie graph showing distribution of ocular trauma

The mean age of trauma was 32.78 years with SD 16.97. Ocular trauma mostly occured between $30-50$ years $(41.3 \%)$

$18.26 \%$ were between 1-15 years, $28.24 \%$ were between $15-30$ years, $11.53 \%$ were $>50$ years.

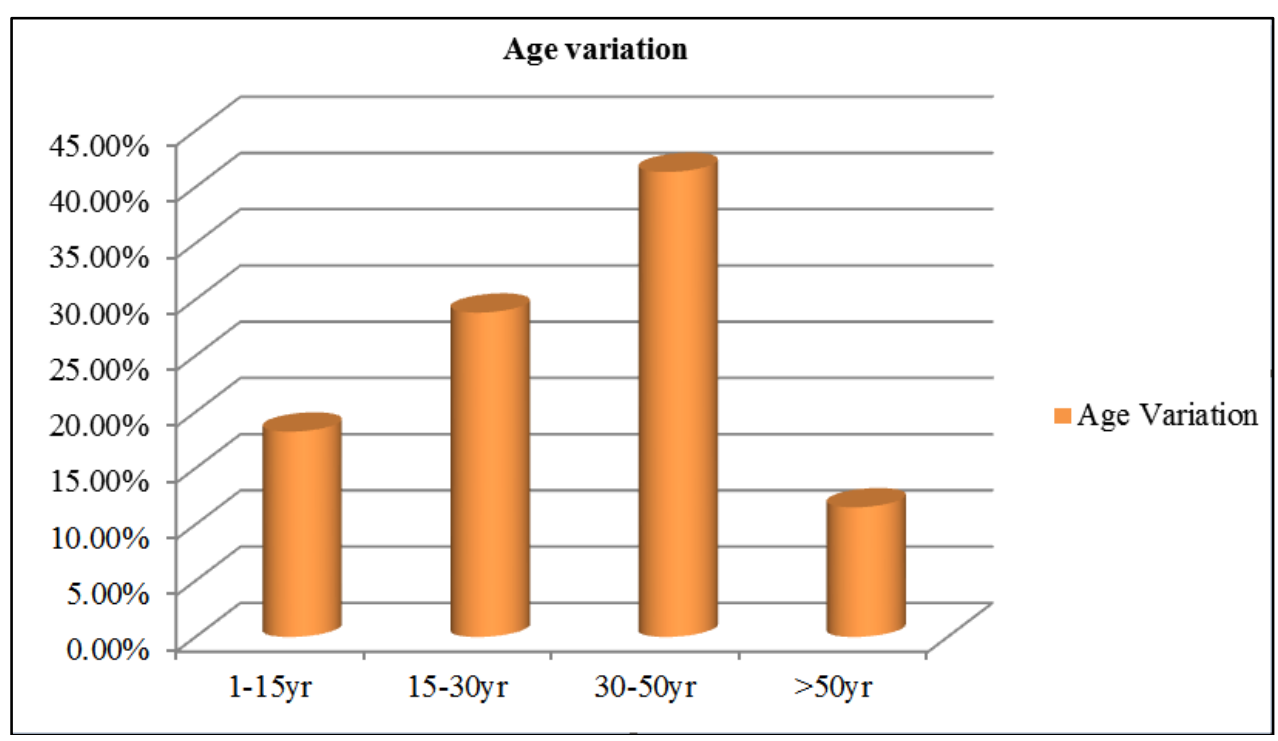

Fig 3: Bar graph showing age variation in ocular trauma

Majority of the cases(58.5\%) had visual acuity between 6/6-6/18,19.23\% had visual acuity between $6 / 18-6 / 60,13.4 \%$ had $6 / 60-\mathrm{CF}$ at 1 meter,5.7\% had CF at 1 meter to PL+ve and only in 3 patients visual acuity presentation

\begin{tabular}{|l|c|c|}
\hline $\begin{array}{c}\text { Visual acuity at } \\
\text { presentation }\end{array}$ & Number & Percentage \\
\hline $6 / 6-6 / 18$ & 61 & $58.65 \%$ \\
\hline $6 / 18-6 / 60$ & 20 & $19.23 \%$ \\
\hline 6/60-CF @ 1mtr & 14 & $13.46 \%$ \\
\hline CF@1mtr-PL +ve & 6 & $5.7 \%$ \\
\hline Unable to measure & 3 & $2.8 \%$ \\
\hline
\end{tabular}


Table 3: Showing clinical finding at the time of presentation

\begin{tabular}{|c|c|}
\hline Closed globe injury & Open globe injury \\
\hline $\begin{array}{l}\text { Total-81(77.8\%) } \\
\text { 1. Superficial lid injury-11(10.5\%) } \\
\text { 2. Lid tear-7(6.7\%) } \\
\text { 3. Subconjunctival hemorrhage-19 }(18.2 \%) \\
\text { 4. Conjunctival FB- } 8(7.6 \%) \\
\text { 5. Corneal FB-13(12.5\%) } \\
\text { 6. Chemical injury-5(4.8\%) } \\
\text { 7. Epithelial defect-14(13.4\%) } \\
\text { 8. Corneal ulcer-3(2.8\%) } \\
\text { 9. Traumatic optic neuropathy-1(0.9\%) }\end{array}$ & $\begin{array}{l}\text { Total Penetrating injury-23 } \\
\quad(22.1 \%) \\
\text { 1. Zone I-13(12.5\%) } \\
\text { 2. Zone II-7(6.7\%) } \\
\text { 3. Zone III-3(2.8\%) }\end{array}$ \\
\hline
\end{tabular}

The categories of injury showed that $81(77.8 \%)$ had closed globe injury and $23(22.1 \%)$ had open globe injury. Among the closed globe injury subconjunctival haemorrhage $(18.2 \%)$ was the most common finding followed by epithelial defect (13.4\%). The open globe injury was classified by BETT, among it zone I (12.5\%) injury was the most common.

Home, road and field were the most common location of ocular injury. Foreign body, stick, lime and stone were the most common offending agent. Orbital trauma occurs most commonly among farmer followed by student, house wife, and driver in decreasing order.
Between 1-15 years age group most common location of injury were school (54\%) and play ground $(46 \%)$. In $15-30$ year age group home was the most common location of injury followed by road (25.8\%). In 30-50 years age field (37.2\%) was the most common location of injury followed by home $(32.5 \%)$ and road $(25.8 \%)$ in decreasing order. In patients more than 50 years, field $(71.4 \%)$ was the most common location of injury.

The association between age of ocular trauma and location of injury was clinically significant with $\mathrm{p}$ value 0.05 .

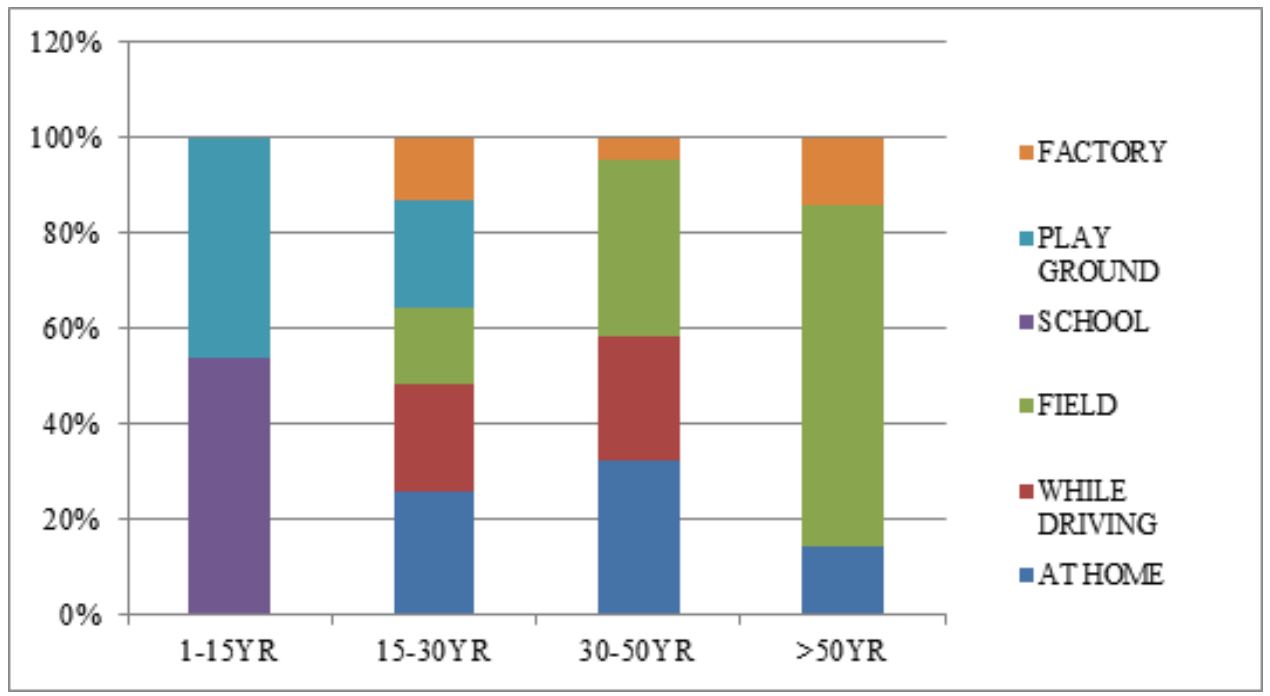

Fig 4: Bar graph showing correlation of location of injury with age

Among 1-15years (100\%) and 15-30 year (35.4\%) age group most of them were students. In between 30-50 years $(34.8 \%)$ and $>50$ years $(64.2 \%)$ most of them were farmers. The association between age of ocular trauma and occupation was clinically significant with $\mathrm{p}$ value 0.041 . 


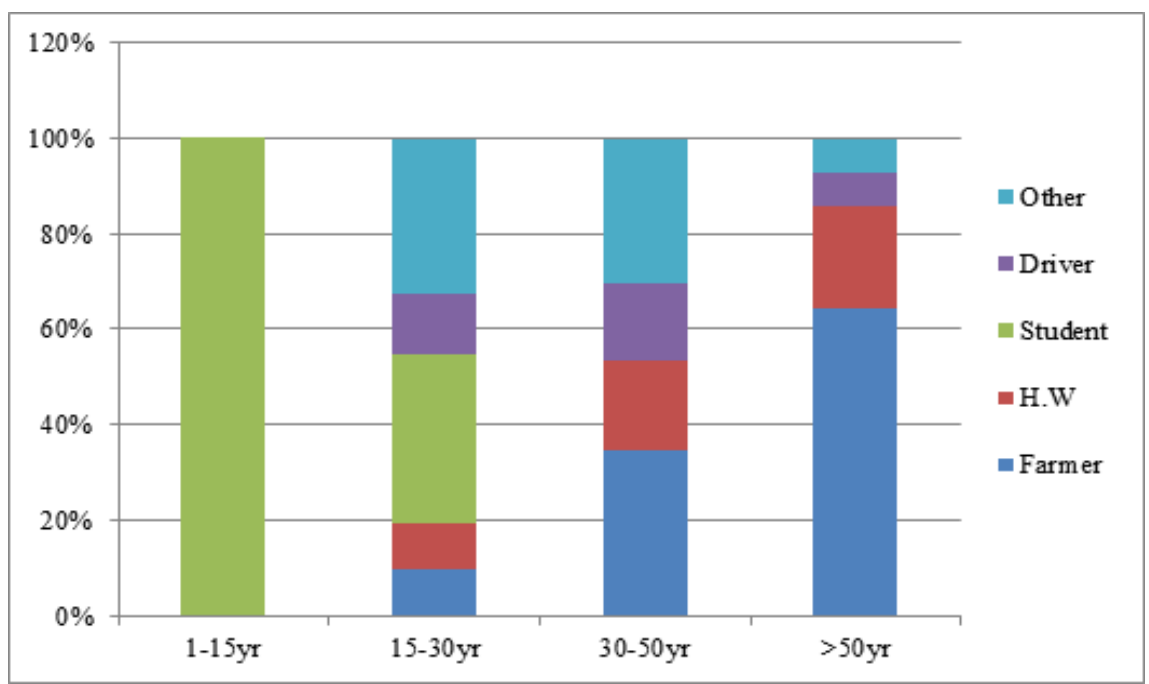

Fig. 5: Bar graph showing correlation of age with occupation

Table 4: Showing correlation between gender and location of injury

\begin{tabular}{|l|c|c|}
\hline $\begin{array}{c}\text { Location of } \\
\text { injury }\end{array}$ & Male & Female \\
\hline At home & $14(20.58 \%)$ & $15(41.6 \%)$ \\
\hline While driving & $15(22 \%)$ & $4(11.1 \%)$ \\
\hline Field & $24(35.29 \%)$ & $7(19.4 \%)$ \\
\hline School & $3(4.4 \%)$ & $4(11.1 \%)$ \\
\hline Play ground & $8(11.7 \%)$ & $5(13.8 \%)$ \\
\hline Factory & $4(5.8 \%)$ & $1(2.7 \%)$ \\
\hline
\end{tabular}

Most common location of injury among male was field $(35.29 \%)$ followed by road (22\%) and among female most common location was home $(41.6 \%)$.The association between gender and location of injury was clinically significant with $\mathrm{p}$ value 0.0013 .

Table 5: Showing correlation between occupation and gender

\begin{tabular}{|l|c|c|}
\hline \multicolumn{1}{|c|}{ Occupation } & Male & Female \\
\hline Farmer & $23(33.8 \%)$ & $4(11.1 \%)$ \\
\hline H.W & & $14(38.8 \%)$ \\
\hline Student & $15(22 \%)$ & $9(25 \%)$ \\
\hline Driver & $15(22 \%)$ & $0(0 \%)$ \\
\hline Teacher & $1(1.4 \%)$ & $2(5.5 \%)$ \\
\hline Clerk & $2(2.9 \%)$ & $1(2.7 \%)$ \\
\hline Factory worker & $3(4.4 \%)$ & $1(2.7 \%)$ \\
\hline Cooley & $4(5.8 \%)$ & $1(2.7 \%)$ \\
\hline Others & $5(7.3 \%)$ & $4(11.1 \%)$ \\
\hline
\end{tabular}

Most common occupation among male with ocular trauma were farmer $>$ student $>$ driver. Most common occupation among female were home maker $>$ student. Correlation between occupation and gender of ocular trauma was clinically not significant with $\mathrm{p}$ value 0.08 .

\section{Discussion}

In this retrospective study of 104 patients presenting after ocular trauma the prevalence of ocular trauma in this study was $0.09 \%$, majority of the patients were males $(65.38 \%), \mathrm{M}$ : $\mathrm{F}$ is $1.8: 1$. This could be due to involvement of male in outdoor activities, similar observation was noted by Rafindadi A et al. (2013), Vats S et al. (2008) and Soyelu M. et al.(2010). ${ }^{5-7}$

Average age of presentation was 32.78 years with SD 16.97 years, with range from 1year to 70 years and most of them were between 30-50 years (41.3\%), but study done by Rafindadi A et al. (2013) among 142 patients over periods of 2 years reported that, most common age of presentation was between 16-30 years (33.1\%), followed by age group 0-15 years (32.4\%). Even study done by Soyelu M. et al. (2010) most common age group was between. Between 0$15 y e a r s$.This variation is because, majority of the study population were student who were educated enough to consult a doctor after an ocular injury. Education and preventive method at working environment and school may reduce the prevalence of the ocular injury., 5 .

Most common location of injury was field followed by road as majority of patient were farmer by occupation followed by student and driver. Soyelu M. et al. (2010) on ocular trauma in Turkey reported that ocular trauma among 250 patients, most (72\%) patient had open globe injury and most of them had occured on the street. The reason for this differences was most of our patients were from rural area who were farmer by occupation as agriculture was the main form of earning and the second reason was high prevalence of road traffic accident in Turkey which led to ocular injury. Study done by Ostadi-Moghadan et al. in Mashhad reported $28.8 \%$ ocular injuries among factory worker, due to lack of sufficient precautionary measures. ${ }^{5,8}$

In our study most common offending agent were foreign body followed by stick, lime and stone in decreasing order. Study done by Mccarty CA et al. 
showed that stick and stone were the most common offending agent, but in contrary Soyelu M. et al. (2010) found that most common offending agent was metallic objects (72\% injury was open globe injury). Study done by Poon et al in rural area of Tanzania showed that wood chips was the most common offending agent,observed in worker and farmers. ${ }^{5,9,10}$

In our study we found a significant correlation between age of ocular trauma and location of injury, in paediatric age group most common location of injury was school and play ground, while Thompson et al. reported that most of injuries in paediatric population took place at home. This difference was because playing behaviour of Indian children was different from Australian children. ${ }^{11}$

\section{Conclusion}

Considering the prevalence, middle aged men are more vulnerable to ocular trauma mostly while working at field or driving. Prognosis might be challenging. Appropriate education for eye protection and use of safety measures, would help in reducing ocular morbidity. Educating for timely treatment and intervention after injury is helpful for saving vision.

\section{References}

1. Karbakhsh DM, Mansouri M, Salimi J, Khaji A, Zareei MR. The pattern of assault-related eye injuries in forensic medicine clinic, Farabi Hospital, 1992. Scientific Journal of Forensic Medicine.2003;9(30):69-74.

2. Soliman MM, Macky TA. Pattern of ocular trauma in Egypt. Graefes Arch Clin Exp Ophthalmol.2008;246:205-212.

3. Alishir AA, Saeidi Far MR, Pakdel F, Farshadi M. Comparative study of the rate and causes of eye injuries in patients admitted to Shahid Mohammadi hospital in Bandar Abbas during 1998-1999 and 2004-2005. Medical Journal of Hormozgan University.2007;11(3):195-200.

4. Balaghafari A et al. Ocular Trauma: 2 Years Retrospective Study in Sari, Iran. Mater Sociomed. 2013;25(4):230-232.

5. Rafindadi A et al. Orbital and ocular trauma at Ahmadu Bello University Teaching Hospital, Shika-Zaria:A retrospective review. Annals of Nigerian Medicine. 2013;79:20-23.

6. Soylu M, Demircan N, Yalaz M, Isiguzel I Etiology of pediatric perforating eye injuries in Southern Turkey. Ophthalmic Epidemiol.1998;5(1):7-12.

7. Vats S, Murthy GVS, Chandra M, Gupta SK, Vashist $\mathrm{P}$, Gogoi M Epidemiological study of ocular trauma in an urban slum population in Delhi, India. Indian $J$ Ophthalmol.2008; 56:313-316.

8. Ostadi-Moghaddam H, Fotouhi A, khabazkhoob M, Heravian J, Yekta AA. Prevalence and Risk Factors of Refractive Errors among schoolchildren in Mashhad, 2006 -2007. Iranian Journal of Ophthalmology. 2008;20(3):3-9.

9. McCarty CA, Fu CL, Taylor HR. Epidemiology of ocular trauma in Australia. Ophthalmology 1999;106:1847-52.

10. Poon A, McCluskey PJ, Hill DA: Eye injuries in patients with major trauma. J Trauma 1999;46:494-499.

11. Thompson CG, Kumar N, Billson FA, Martin F. The aetiology of perforating ocular injuries in children. $\mathrm{BrJ}$ Ophthalmol.2002;86:920-922. 